\title{
An Observational Study Of Verbal And Nonverbal Communication In Female And Male University Students
}

\author{
Aliyah Ali \\ \& \\ Shagufta Nasreen \\ Women's Studies \\ University of Karachi \\ M. Abuzar Wajdi \\ Institute of Health \& Business Management \\ Jinnah Sindh Medical University
}

\begin{abstract}
Gender based sociological and linguistic studies show that differences exist in communication style of men and women, boys and girls. Although many gender stereotypes have changed with modernization and awareness about gender issues however common assumption is that 'girls are talkative' and boys are 'less emotional'. In the context of transitions in culture and society, this study explored verbal and nonverbal communication differences among male and female university students. Using purposive sampling method, male and female students were observed in three types of groups sitting at different social spots in University of Karachi. In total 30 male and 30 female students were observed for verbal and nonverbal communication. The units of observations were Paralanguage (words, pitch, volume, speaking rate) for verbal communication and gestures, facial expressions, eye contact, distance and space when sitting and standing. Results showed that overall both boys and girls were talkative and used slang language within same sex groups. However, the topic of discussion was personal for girls and politics for boys. Females kept a space and distance while sitting and standing as compared to boys. Within groups, male and female student's body language showed superiority. The study has limitations therefore generalization of results for other gender-typed situations are not promising. Future studies could examine in other situations where status and power difference exist within relationships.
\end{abstract}

Keywords: Verbal Communication, Non-Verbal Communication, Observation.

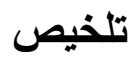

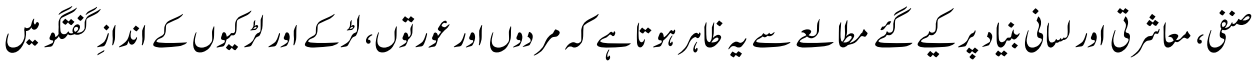

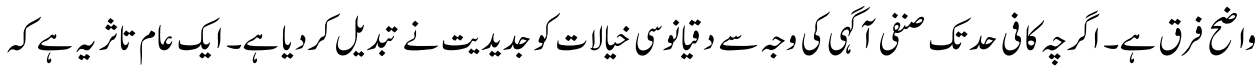

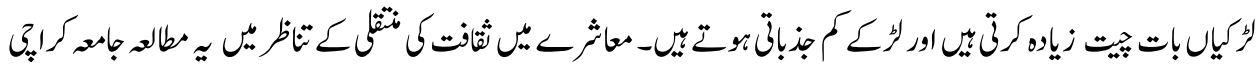

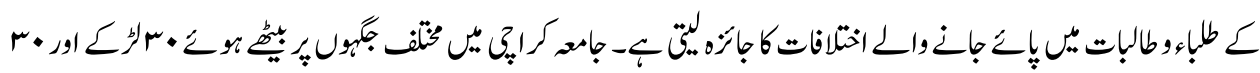




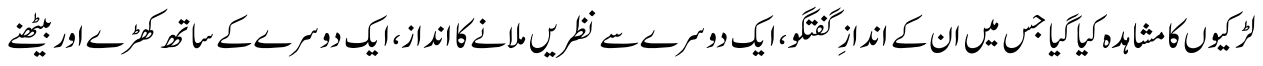

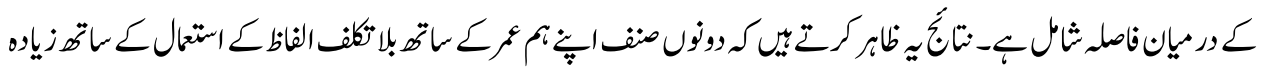

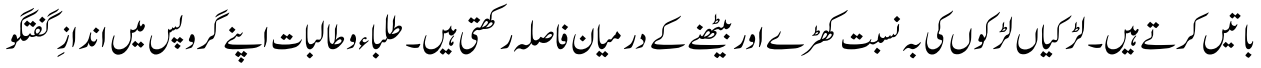

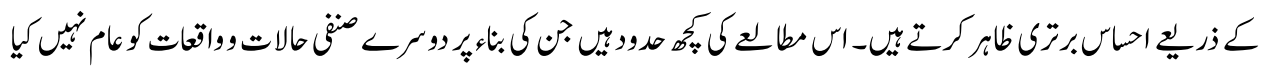

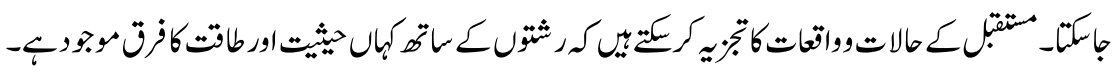

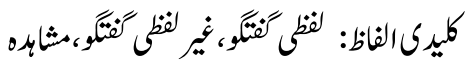

\section{Introduction}

Communication and language are two important ways that connect people and also shape the concept of gender with passage of time. Gender differences in communication have attracted researcher's attention in sociology and linguistics. Researchers have substantiated in earlier studies that verbal and non verbal communication patterns of men and women are quite different (Eagly \& Johnson, 1990; Kring \& Gordon, 1998). Gender differences at work place and education has been studied in the context of Pakistani Culture (mention studies) however there is less focus on verbal and non-verbal communication in educational institution. It is important to study the differences because Pakistani society is in transition and new gender identities and roles are emerging. Gender differences in communication include verbal aspects such as language style, content of speech and how talkative is someone (Tannen, 1990) and non-verbal aspects such as body posture, space, eye-contact, way of sitting and standing, moving hands during talk (Andersen, 1999). Earlier research shows that there are distinct communication differences for males and females. This research is important because gender stereotypes creates identities and roles that are assumed to be fixed and natural such as girls are shy and soft spoken while boys are aggressive and loud. The communication study is dynamic opine that gender is not fixed but is changing process. Hence this research in continuation of past communication researches explores that how communication creates gender.

Perry (1992) explains communication as the way to express opinions, emotions and feelings. Communication skills such as reading, writing and speaking vary for people and it is influenced by different settings and shapes ideas and information prevailing in the society or among individuals. The purpose of communication is to teach and learn new knowledge, skills to be progressive. Thus communication is essential for human interaction between children and parents, among workers, between employers and workers and for social development or even husband and wife. However people's diverse nature and characteristics affects the way they communicate. 
DeFrancisco \& Palczewski (2007) focus on the social constructionist approach to understand gender and communication in contrast to the how gender influences communication approach. The way male and female communicates is interesting as the gender does matter in communication but first it is important to understand gender. The word gender and sex is often used interchangeably however the definition of words is not same. The word sex means biological difference between male and female, and gender means the socio- political constructed roles of males and females given by any society (Lippa, 2002). Therefore gender focuses on the psychological, cultural and behavioral traits associated with one sex. Interaction among culture, society and environment developed the roles, responsibilities, expectation and aptitude were developed and learned by males and females of vary society and modified. There are two theories about gender, one is the essentialist and the other is the social constructionist. According to the essentialist view we are born with gender traits. On the other hand social constructionist presents the view that attributes, characteristics, behaviors and expectations from males and females are socially constructed (Jihn\& Janet, 1998).

Various researches conducted in the past explore that generally the verbal and non verbal communication patterns of men and women are quite different (Eagly \& Johnson, 1990; Kring \& Gordon, 1998). The important factors to develop the communication patterns are personal traits (Feingold, 1994), experiences from socializing processes (Eagly, 1987), and status in society (Hollingshead, 1996). Further, living in specific social communities and their status is reflected from communication styles. In social interaction when individuals interact and communicate their behaviors are reflective of the social group and social status of all interaction partners in that situation. Diversity in gender roles is reflected in communication at individual, interpersonal and societal level. Holmstrom (2009) argues that gender differences in communication exist as women are akin to listening and comforting skills while men value the narrative and persuasive skills.

Many people have the ability in verbal communication and many other individuals have the skills to consider non verbal interactions. The research studies reinforce the focus on both the microscopic and the macroscopic levels of communication. The performance of verbal and nonverbal behavior is concerned with microscopic level and globally behaviors were evaluated by macroscopic (Canary \& Dindia, 1998). The right side of the brain governed the nonverbal communication and left side rule the verbal (Andersen, 1999). For instance people who have the trauma of right side of the brain also fail to learn the facial expressions but able to continue verbal communication. On the contrary, people whose left side of the brain damaged they are failed to understand language, to speak and read. Verbal and non verbal communication is also different in content and composition. Non verbal communication communicates emotions in terms of content (Owen, 2011).

Gender differences in communication are studied from different perspectives. Women are influenced from communication skills since their childhood. In every span of life male and 
female speak and express feelings differently as to support situation and in conveying messages women provide detailed information than men (Burleson et al, 2011). Another research (Tenenbaum, Ford, \& Alkhedairy, 2011) identified that parents style of communication influenced the children and they copy their style when in conversation with their siblings. The interesting fact is that mothers of daughters usually use more sentimental words than mothers of sons when talking to their children (Tenenbaum et al. 2011, ). Whereas, girls learn emotional communication style from their mothers and boys enforce to show fearless and do rough and aggressive conversation. In different age groups the etiquette of conversation have developed the different communication styles as apart from age same rules applied to same sex dialogues (Croft, Boddy, and Pentucci, 2007).

According to many published research work bias in gender differences has two forms a) alpha which shows an overrated difference (b) beta which suppose that between the sexes there are a few differences (if exist) (Canary \& Dindia, 1992). According to the bias approach, "similarities rather than differences characterize men and women" and that while "some noteworthy differences between men and women exist, when both withinand between-gender comparisons are made; the similarities are as important--if not more important--than the differences" (Canary \& Dindia, 1992)).

Another important aspect of communication is nonverbal communication as stated by DeFrancisco \& Palczewski (2007) 'how our body does gender'. Nonverbal communication is known to be the reliable source of communication along with the important source of information for research on human behaviours (e.g., Bull, 2002; Duncan, 1969; Frels \& Onwuegbuzie, 2013; Mehrabian, 1981, 2009; Morris, 1977). South Asian culture is not an exception where expression of bodies for males and females differ. Women are expected to sit and stand with tight body while men can be more open not crossing their legs and standing free. Eye contact, voice and use of words in same gender groups and different gender groups vary as well. In this paper we explore what are the verbal and nonverbal differences among young males and females.

\section{Literature Review}

The topic of gender differences in social behaviors is not new. In 1974 Maccoby and Jacklin's The Psychology of Sex Differences introduced several pioneering theories. According to their observation based analysis they observed a lot of personality and behavioral differences between men and women due to many social and biological causes. Interestingly these differences were shown more clearly with in groups (among women and among men) than between gender groups. This research opens new areas for other researchers. They explore first that men were more dominant and aggressive than women but women were higher in affection, acceptability and concerned. These findings were proven right by another study by Feingold (1994). By using meta-analysis, Fein Gold identified that in America, male participants were bold and confident overall compared to 
women. While women were more superior in extraversion, trust, nurturance, and general anxiety.

As mentioned before men and women have different styles of communication as "debate vs. relate" "report vs. rapport", "competitive vs. cooperative". As Kohlberg explained the levels since childhood how these differences develop in males and females preconventional, conventional, and post conventional. Each level has its own categories but in the conventional level stage 3 is the concept of "Good boy, Nice Girl orientation". As the children grow this concept was build up in their minds that their body language, conversation and behavior should be nice to others moreover according to the society approval. This thinking also made gender differences in verbal and non verbal communications as girls should be soft spoken, cooperative and composed in their gestures and postures as well as boys can be loud, decisive in speaking and graceful in their gestures and postures (Kohlberg,). This fact also proven by the work of Vygotsky (1962) that children's environment in which they grow up influence their thinking and social interactions which is connected with their language and ways of communication.

A number of causes develop gender differences in social personality traits and behavior. For example social behavior linked to biological characteristics which are permanent and natural. Particularly evolutionary causes were attributed to nurturance, dominance and aggression. As per evolutionary psychology reproductive health develop the feeling of aggression in men and nurturing behaviors in women (Archer, 1996). According to Nolen - Hoeksema (1987) different hormone levels of men and women and chromosomal differences were responsible for depression, anxiety and neuroticism. In a recent study a bio-psychosocial framework in which men and women differences regarding social interactions created by brain structure, function, and chemistry were discussed that how gendered communication was caused by certain sex-based brain differences.

According to Jennifer Coates (1986) found through only male and only female discussion groups that during conversation women revealed more about their private lives have long talks on one topic and let everyone participate, whether men avoid to talk about their personal life or emotions they rather talk about current affairs to show that they are well informed about worldly situation and sport and travel etc. Males change topics more rapidly and speak very less also some men tried to be dominating in her book Women, Men and Language (New York: Longman Inc., 1986). Gender differences show both in professional and social settings. It is no wonder that art of conversation is the key to success.

The young people have various methods for correspondence verbally and nonverbally. These distinctions are obviously been seen in their practices. In another research of Mexican and Central American grade school students ' play ground exercises close Los Angeles , Linguist Marjorie Goodwin (1998) found that the children played in same sex 
gatherings, yet the young girls playing hopscotch were profoundly focused and speedy to call others" out of the line". In an examination of mainland Chinese and U.S. youngsters' play, the U.S. boys were to establish to be more emphatic than the girls in same sex play, yet the switch was valid for the Chinese kids. Language specialist Penelope Eckert calls attention to that the idea of play as a rule changes from youth to pre-adulthood. She recommends that this change is straightforwardly connections to gender and heterosoi ability, or the strain to make a hetero character, and that language assumes a focal job in this move especially for girls. She saw those children's play ground action changes from making recreations to performing manliness as competitors. Young girl's play ground exercises changes from recreations to "standing, sitting, or strolling around the outskirts, viewing the young men, harassing them, or talking strongly together. This discussion movement is an expertise that young girls deliberately create. However specialists utilizing the hypothesis guarantee that standards of sex segregated data children's play set the establishment for restricting adult feminine and manly styles of discussion.

The style of communication or conversation shows patterns and capabilities of communication. The word patterns highlights that a person does not always behave in exactly the same way but changes behavior with time and these changes are described for that person by other people. Verbal communication and nonverbal communication have separate evolutionary functions and has a diverse past. As verbal communication has cultural biasness while non verbal communication is biologically based. The evidence is a few non verbal communications same in all cultures but all systems of verbal communication does not have the same meaning in whole world (Andersen, 1999).

Historically nonverbal communication was also developed before verbal communication and proved to be an initial and essential support of humans and also create verbal communication later. As discussed before that men and women have different ways to communicate both in verbal and non verbal. Although many non verbal characteristics influenced the way of communication as the rate of speech, pitch, vocal inflection, words pronunciation, volume, amount of talk and silence and even favorite subjects of talk. Culture also influenced the verbal and nonverbal communication as ethnicity, race, social class, national origin, region of the country and language (Carbaugh, 2002; Kikoski \& KiKoski 1999; Kochman 1990). Many authors have debated the true meaning and objectives of silence people often adopt during conversation. As Mazzei (2008) study the personality and intention which she termed as "racially inhabited silences".

\section{Communication Approaches}

One reason that people vary in their utilization of nonverbal correspondence is that their explanations behind imparting are frequently unique, as indicated by John Gray, creator of the success "Men are from Mars, Women are from Venus." Men for the most part convey 
to transmit data and take care of explicit issues, while women generally use correspondence to express sentiments and accomplish enthusiastic closeness. Thus, women will in general utilize nonverbal correspondence more than men. Jo Freeman, creator of "Women: A Feminist Perspective," asserts that men depend on progressively evident motions and are bound to utilize their hands to communicate. Women, then again, will in general utilize progressively unpretentious and controlled signals and display respectful motions, for example, bringing down the eyes when hindered or stood up to.

Men will in general favor up close and personal correspondence, while women are typically similarly agreeable one next to the other with their accomplice. As per their more noteworthy want for touching, women are commonly more tolerant of close real vicinity than men; truth be told, men are bound to see touching as an indication of forceful or fierce purpose.

By the by, various societies have various resilience's for real closeness, and these distinctions regularly surpass the contrast between gender roles. Contacting since men are almost certain than women to connect contacting with sexual expectations, hetero men are more averse to utilize contact during discussion with other men. Women, then again, are far less hesitant about contacting other women since they likewise utilize contacting as a declaration of fellowship or compassion.

\section{Feminist Perspective}

It is universally understood that language brings revolution in world. Its main function was to communicate and to show the social changes. Language also has a strong relationship with power. Many social thinkers, anthropologists, linguistics and feminists agreed on that point that power and discourse has linkage. In the socialization process language plays an important role. But gender differences in language also exist, which was identified by Jesperson (1922) in The Woman as "women's language is something deviant from the standard, men's language". However, feminist movement's role should not be forgotten which truly highlights the issue of gendered language. The socio-political context in which the language was spoken matters a lot. Another important point raised by feminist movement is the language used by women and the language used about women by men. The term "power' actually shows these gender differences as the word of power is used in the meanings of influencing others often associated with men( Siddiqui, 2014).

Many researchers stated that children sense danger and express it through facial expressions (e.g., Abramovitch, 1977). The research studies on non verbal communication and linguistic expression combined proved to be use ful on aphasia regarding neurolinguistic (e.g., Loveland et al., 1997; McNeill, 1985), the findings from the researches on autistic children non verbal communication are very helpful in 
collecting information. To avoid deception detection researchers have developed assessment of non verbal communication as essential part (Ekman \& Friesen, 1974; Ekman, O'Sullivan, Friesen, \& Scherer, 1999; Fiedler \& Walka, 1993; Warren, Schertler, $\&$ Bull, 2009). Non verbal communication can provide support in business sector in taking decisions (e.g., Manusov \& Patterson, 2006).

According to Mehrabian (1981) 93\% of people feelings and behaviors formatted through paralingual and facial expressions (i.e., facial expressions 55\%, and paralingual $38 \%$ respectively). Additionally verbal and nonverbal phenomenon process in different parts of mind (e.g., Kelly, Barr, Church, \& Lynch, 1999), which creates connectivity and interdependence (e.g., Bull, 2002; Jones \& LeBaron, 2002; Kendon, 2000, 2004; Knapp \& Hall, 2010; Manusov \& Patterson, 2006). Empirical knowledge is also lacking about how qualitative researchers used non verbal communication data and to what extent to improve their studies (Onwuegbuzie, Leech, \& Collins, 2010) undeniably, exemplar models (e.g., Ekman\& Friesen 1974).

The purpose of the present study was to explore the gender effect on verbal and nonverbal communication style. Female and male university students were observed while sitting out of the classrooms in male groups, female groups and mixed groups. It was expected that the study will be in line with earlier researches showing different interactions in different gender groups. Further it was expected that differences may be observed as compared to pre-conceived notations about young boy's and girl's behaviors discussed in earlier researches?

\section{Methodology}

The study was conducted purposively selecting groups of students sitting and relaxing at different social spots in campus. Each researcher observed one group with all females, one group with all male students and a mixed group of students. In total, 30 male and 30 female university students were observed. The study was conducted in University of Karachi. No demographic information was collected as the method of data collection was observation. Observation is a category of qualitative research method. In this type of research the researcher observe different groups of people without any interference and is not a member of the group (Onwuegbuzie et al, 2010). On average the age group was between 18 to 20 years male and female students. The groups of students were randomly observed at different places out of the classrooms and departments interacting with same gender and mixed gender groups. The groups were observed to collect data about language, content, eye-contact, way of sitting and standing using the following framework. 
Table: 1

Vocal and nonvocal elements of communication

\begin{tabular}{|l|c|c|}
\hline & Verbal Communication & Nonverbal Communication \\
\hline Vocal & Spoken words & Paralanguage (words, pitch, volume, speaking rate) \\
\hline Non-vocal & Body language & (gestures, facial expressions eye contact, distance \\
& & and space)
\end{tabular}

Source: Adapted from Owen Hargie, Skilled Interpersonal Interaction: Research, Theory, and Practice (London: Routledge, 2011), p. 45.

Observations were made with the help of five undergraduate female students who were initially briefed about the process and procedure. There were several limitations to this study. First, an observational study cannot directly examine the cause of the verbal and nonverbal behavior in an uncontrolled environment. Secondly, the groups of students were observed at different places randomly; therefore generalization of data is difficult. The students who were observed realized that they were being observed but were unaware of the purpose of observations. They received a debriefing about the objective of the research after observations.

\section{Results \& Discussion}

The primary goal of analysis was to examine differences in verbal and nonverbal communication of male and female students outside the classrooms.

Gender Differences in verbal and nonverbal communication among students

\begin{tabular}{|l|r|c|}
\hline Communication & $\begin{array}{l}\text { Male } \\
\text { group of } \\
\text { students }\end{array}$ & $\begin{array}{l}\text { Female } \\
\text { group of } \\
\text { students }\end{array}$ \\
\hline Verbal & & \\
\hline Words (Use of slangs) & $5 / 30$ & $1 / 30$ \\
\hline High pitch & $19 / 30$ & $3 / 30$ \\
\hline Talk with High Volume & $21 / 30$ & $5 / 30$ \\
\hline $\begin{array}{l}\text { Topic of discussion } \\
\text { Politics }\end{array}$ & $24 / 30$ & $6 / 30$ \\
Personal issues & $4 / 30$ & $26 / 30$ \\
\hline Speaking rate & $24 / 30$ & $6 / 30$ \\
Rapid & & \\
\hline Nonverbal & $11 / 30$ & $19 / 30$ \\
\hline Expressive & $15 / 30$ & $15 / 30$ \\
\hline Eye contact & $6 / 30$ & $27 / 30$ \\
\hline Distance and space during conversation(yes) & $21 / 30$ & $9 / 30$ \\
\hline Touch & & \\
\hline
\end{tabular}

Source: Observations in the research for verbal and nonverbal communication 
The table above shows that communication differences exist between male and female students. However,

Observations:

Mixed group

A mixed group of students with three boys and four girls were playing a board game sitting in social interactive space called "Arts lobby". It's a space connecting corridors of majority of Arts departments, majority of students get interacted here and use it as a social space. Sitting on the floor the main topic of discussion was winning of Pakistan's cricket team. They were discussing about a cricket match which Pakistan won from Bangladesh and Bengali female fans were showed crying on TV after losing the match. Boys were loud and stressing that 'all girls are emotional' by giving example of those female fans of the loosing team. The boys were constantly using slangs such as "abbey chal" "chamat parey gay" with each other, while girls were using "hey dude' and 'seriously' again and again. Boys were touching each other more as compared to girls and were louder and cracking jokes. The group was observed for thirty minutes.

The two culture theory of gender and communication proposed that both girls and boys are raised in segregated gender/sex language spoken communities which format their speaking style in opposite ways. As often seen in children's playing, girls copy their mother or elder sister's style and boys followed their fathers and elder brother. Girls like to play in smaller groups where they can easily talk. According to communication scholar Julia Wood (2007)the summary of girls play is they do mutual and cooperative talk to develop and sustain relationships, they do avoid criticizing, outdoing or make others feel embarrass . On the other hand boys like to play in large groups which are less emotional, focus on activities not conversation be competitive and asserting one's independence. The objective of this group is to achieve some goal.

\section{Girls Group}

A group of five girls standing in another department discussing about diet plans. Three of them were skinny while one of them was fat. Her peers were suggesting diet plans and she was listening very carefully. She seemed desperate to lose weight. She appeared nervous and had lack of confidence. She was continuously setting her scarf and her body language showed that she was feeling less confident. The skinny girl on the other hand was very loud, funny and hosing off that she is 'superior'. She was 
running her hand through her hair, then she tied them up and after two or three minutes again she unties them. Another girl was using words "like" and 'literally' repeatedly in her conversation. It was fifteen minutes observation.

Pakistani culture is quite different from other culture and in construction of gender roles is complicated because it's a mixture of religion, rituals of family and cast, societal hierarchies and modernization. Therefore the role of men and women and how to communicate with others is also different. Since childhood a girl has been started to learn how to talk, sit and listening to others, moreover her body language also matters. Boys too learn all these ways accordingly. These factors can be explained by Gorden's (1980) indicators are the typology of nonverbal communication

": kinesics (i.e., behaviors reflected by body displacements and postures), proxemics (i.e., behaviors denoting special relationships of the interviewees/interviewers), chronemics (i.e., temporal speech markers such as gaps, silences, and hesitations), and paralinguistics (i.e., behaviors linked to tenor, strength, or emotive color of the vocal expression). For instance, with respect to silence, qualitative researchers can glean important information from silence exhibited by participants - indeed, sometimes more can be learned from what a person does not utter than from what he/she utters".

\section{Boys group}

The third observation was in an Arts department. A group of five male students, standing and discussing politics. One boy had long hair and a beard. He was quite loud and blaming politicians for all the problems of the country. During conversation he was acting superior and his body language was confident. In fifteen minutes he used abusive word ' $k a m i n a$ ' (a mean person' at least 10 to 15 times. It was not used as an abuse rather as slang between friends. All boys were punching each other and laughing a loud.

It is very interesting that the verbal behaviors of men and women show their subordinate or super ordinate position (Johnson, 1994). Though non verbal communication was also dependent on the conditions and gender roles no doubt in it that in Pakistani society men have all powers and authority over women in both public and private sphere which even shows in their student life. As discussed above communication is the means by which ideas and information are spread from person to person. However, interestingly men and women differ psychologically from the way in which they communicate to influence others. Academic researches prove that women tend to be more expressive, tentative, and cooperative and have polite communication characteristics while men use more 
aggressive, assertive, direct and powerful communication traits. The non verbal communication although difficult to observe but commonly many things we heard and said about these differences as we are habitual to say boys that "don't cry like girls" or don't walk like girls as Marion Young (1990) discussed Straus's observation in regard to what it means to "throw like a girl" as boys are taught to throw "walking like a girl, tilting her head like a girl, standing and sitting like a girl, gesturing like a girl, and so on. The girl learns actively to hamper her movements. She is told that she must be careful not to get hurt, not to get dirty, not to tear her clothes, that the things she desire are dangerous for her. Thus she develops a bodily timidity that increases with age.

These factors can be related to our research findings as $37 \%$ boys showed less expressions when it comes to non verbal communication and $37 \%$ boys also avoided eye contact while having a conversation. While $70 \%$ girls showed more expressions during conversations also $17 \%$ women were moving their hands and arms. It was observed that during verbal communication $63 \%$ boys used high pitch tone and $70 \%$ girls were cracking out jokes during verbal communication. Girls are more inclined to face each other and make eye contact when talking, while men are more likely to look away from each other. Researches on communication differences between men and women has shown that while men are more task oriented, women tend to be more people and relationship oriented in their communication style

Another interesting finding is that both $100 \%$ boys and girls used slang language during conversation but $73 \%$ girls used vocabulary and phrases precisely whether on $27 \%$ boys have this skill. $67 \%$ of girls like to talk about personal issue and $80 \%$ boys were interested in politics. These findings have been supported by another observation based unpublished research conducted by the students of Centre of Excellence for Women's Studies, University of Karachi in 2017. The results of this research showed that girls are more talkative tan boys, girls often talk about domestic issues, fashion and domestic chores whether boys conversation topics were about politics and sports. The group of boys was bigger and girl's sittings were small.

In Pakistani society girls are taught to speak less, in low voice, laugh in low tone and their gestures and postures should be composed, they should walk slowly, whether boys can talk and laugh loudly, walk firmly and masculinity should be shown from their style of verbal and non verbal communication. Many proverbs are famous in our society as "Larkion ki tarah baat kion kar rahay ho haath hila hila kar" why you are talking like girls by waving your hands, or "Larkion ki tarah kion chal rahay ho", why you are walking like girls, as well criticizing girls also "Larkon ki taraz mat betho" do not sit like boys, "Aunchy awaz may mat bolo" do not talk loudly. 
Advancement toward considering verbal and nonverbal conduct simultaneously might be hindered through specific components. Another issue is direct configuration of books and diaries, which is fairly inconsistent by revealing the multidimensional cooperation complications. It is a lot simpler to introduce oral transcription or measurable tables than it is to portray and break down combinations among fluctuated message modalities. Another obstruction is that there isn't far reaching understanding about how all encompassing examinations ought to be directed.

In qualitative research explicitly, a few researchers (e.g., Begley, 1996) have voiced uncertainties that an undocumented, non-rich consideration, or an exclusion of non-verbal correspondence as information, could add to constraints, for example, justification just as the absence of mindfulness by the specialists and, henceforth, compromise the verisimilitude of the naturalistic request. Without a doubt, scientists have exhibited that nonverbal correspondence, for example, hand motions pass on center semantic data past discourse and are basic to semantic correspondence (Beattie and Shovelton, 1999, 2002, 2003, 2005, 2011; Holler, Shovelton, and Beattie, 2009; McNeill, 1992). Others (e.g., Burgoon, 1994; Graham and Argyle, 1975) have contended that progressively significant fundamental implications could be recognized through nonverbal correspondence than through discourse.

\section{Conclusions}

As the study is an observational research it is difficult to identify the root causes of gender differences in verbal and non verbal communication styles of teen ager students of University of Karachi. However confusion about many gestures and postures were cleared for instance usually girls smile more than boys because it's a sign that they were listening attentively. It is highly recommended that in future research studies should examine the gender differences of verbal and non verbal communication behaviors regarding their social status, culture and specific background.

\section{References}

Abramovitch, R. (1977). Children's Recognition of Situational Aspects of Facial Expression. Child Development, vol.48, pp.459-463.

Andersen, Peter A. (1999). Nonverbal Communication: Forms and Functions (Mountain View, CA: Mayfield). 
Holmstrom, Amanda, J. (2009). Sex and Gender Similarities and Differences in Communication Values in Same-Sex and Cross-Sex Friendships, Communication Quarterly, vol.57:2, pp.224-238.

Archer, J. (1996). Sex Differences in Social Behavior: Are the Social Role and Evolutionary Explanations Compatible? American Psychologist, vol.51, pp.909-917.

Brant, R., Burleson, Lisa, K., Hanasono, Graham D., Bodie, Amanda, J. \& Holmstrom, Bull, P. (2002). Communication Under the Microscope: The Theory and Practice of Microanalysis. London, United Kingdom: Psychology Press.

Canary, D. J. \& Dindia, K. (1998). Sex Differences and Similarities in Communication: Critical Essays and Empirical Investigations of Sex and Gender in Interaction. Mahwah, N.J: Erlbaum.

Croft, R., Boddy, C. \& Pentucci, C. (2007). Say What You Mean, Mean What You Say. International Journal of Market Research, vol.49:6, pp.715-734.

DeFrancisco, V. P. \& Palczewski, C. H. (2007). Communicating Gender Diversity: A Critical Approach, Thousand Oaks, CA: SAGE Publications, Inc.

Duncan, S., Jr. (1969). Nonverbal Communication. Psychological Bulletin, vol.72, pp.118-137.

Carbaugh, Dan. (2002). "I can't do that!" But I "can actually see around corners": American Indian students and the study of public "communication". In Judith N. Martin, Thomas K.DAVID CARNES , Do Men \& Women Use Nonverbal Communication Differently? https:/www.livestrong.com/article/172581-do-menwomen-use-nonverbal-communication-differently/ retrieved on $17^{\text {th }}$ June 2019

Ekman, P. \& Friesen, W. V. (1974). Detecting Deception from the Body or Face. Journal of Personality and Social Psychology, vol.29, pp.288-298.

Ekman, P., O'Sullivan, M., Friesen, W. V. \& Scherer, K. R. (1999). Face, Voice and Body in Detecting Deceit. Journal of Nonverbal Behavior, vol.15, pp.125-135.

Eagly, A. H. \& Johnson, B. T. (1990). Gender and Leadership Style: A meta-analysis. Psychological Bulletin, vol.108, pp.233-256. Retrieved from: http://digitalcommons. uconn.edu/cgi/viewcontent.cgi? article $=1010 \&$ context $=$ chip_docs 
Eagly, A. H. (1987). Sex Differences in Social Behavior: A Social Role Interpretation. Hillsdale, NJ: Erlbaum.

Feingold, A. (1994). Gender Differences in Personality: A Meta-Analysis. Psychological Bulletin, vol.116, pp.429-456. http://dx.rdoi.org/10.1037/0033-2909.116.3.429

Fiedler, K. \& Walka, I. (1993). Training Lie-Detectors to Use Nonverbal Cues Instead of Global Heuristics. Human Communication Research, vol.20, pp.199-223. doi:10.1111/j.1468-2958.1993.tb00321.x

Frels, R. K. \& Onwuegbuzie, A. J. (2013, February). Incorporating Nonverbal Communication Data in Interviews: A Mixed Research Framework. Paper Presented at the Annual Meeting of the Southwest Educational Research Association, San Antonio, TX, United States.

Gorden, R. I. (1980). Interview Strategy Techniques and Tactics. Homewood, IL: Dorsey.

Goodwin, M.H. (1998). Games of Stance: Conflict and Footing in Hopscotch, In Kids' Talk: Strategic Language Use in Later Childhood (Susan M. Hoyle, Carolyn Temple Adger, eds.), New York, Oxford University Press, pp.23-46.

Hollingshead, A. B. (1996). Information Suppression and Status Persistence in Group Decision Making the Effects of Communication Media. Human Communication Research, vol.23, pp.193-219. http://doi.org/10.1111/j.1468-2958.1996.tb00392.x

Jennifer, D. McCullough, Jessica, J. Rack \& Jennifer Gill Rosier (2011). Are Gender Differences in Responses to Supportive Communication a Matter of Ability, Motivation, or Both? Reading Patterns of Situation Effects Through the Lens of a Dual-Process Theory, Communication Quarterly, 59:1, 37-60.

Jennifer, C. (1986). Women, Men and Language, New York: Longman Inc.

Jihn, D. DeLamater \& Janet Shibley Hyde (1998). Essentialism vs. Social Constructionism in the Study of Human Sexuality, The Journal of Sex Research, vol.35:1, pp.10-18.

Jones, S. E. \& LeBaron, C. D. (2002). Research on the Relationship between Verbal and Nonverbal Communication: Emerging Integrations. Journal of Communication, vol.3, pp.499-521. 
Kendon, A. (2000). Language and gesture: Unity or duality? In D. McNeill (Ed.), Language and Gesture. Cambridge, MA: Cambridge University Press, pp. 47-63.

Kendon, A. (2004). Gesture: Visible Action as Utterance. Cambridge, MA: Cambridge University Press.

Knapp, M. L. \& Hall, J. A. (2010). Nonverbal Communication in Human Interaction (7th ed.). Boston, MA: Wadsworth/ Cengage Learning.

Kelly, S. D., Barr, D. J., Church, R. B., \& Lynch, K. (1999). Offering a Hand to Pragmatic Understanding: The Role of Speech and Gesture in Comprehension and Memory. Journal of Memory and Language, vol.40, pp.577-592.

Kohlberg, Kohlberg's Stages of Moral Development Lumen, Education, Society ,\& the K-12 Learner https://courses.lumenlearning.com/teachereducationx92x1/chapter/ kohlbergs-stages-of-moral-development/

Kikoski, J.F. \& Kikoski, C.K. (1999). Reflexive Communication in the Culturally Diverse Workplace. Westport, CT: Praeger.

Kochman, T. (1983). Black and White Styles in Conflict. Chicago: University of Chicago Press.

Kring, A. M. \& Gordon, A. H. (1998). Sex Differences in Emotion: Expression, Experience and Physiology. Journal of Personality and Social Psychology, vol.74, pp.686-703.

Lynn, H., Turner, Kathryn Dindia \& Judy, C. Pearson (1995). An Investigation of Female/Male Verbal Behaviors in Same-Sex and Mixed-Sex Conversations, Communication Reports, vol.8:2, pp.86-96.

Loveland, K. A., Tunali-Kotoski, B., Chen, R. Y., Ortegon, J., Pearson, D. A., Brelsford, K. A. \& Gibbs, C. M. (1997). Emotion Recognition in Autism: Verbal and Nonverbal Information. Development and Psychopathology, vol.9, pp.579-593.

Maccoby, E. E. \& Jacklin, C. N. (1974). The Psychology of Sex Differences (Vol. 1). Stanford, California: Stanford University Press.

Manusov, V. \& Patterson, M. L. (2006). The Sage Handbook of Nonverbal Communication. Thousand Oaks, CA: Sage. 
McNeill, D. (1985). So You Think Gestures are Nonverbal? Psychological Review, vol.92, pp.350-371.

McNeill, D. (1992). Hand and Mind: What Gestures Reveal about Thought. Chicago, IL: University of Chicago Press.

Mehrabian, A. (2009). Nonverbal Communication (3rd ed.). Piscataway, NJ: Aldine Transaction.

Mehrabian, A. (1981). Silent Communication: Implicit Communication of Emotions and Attitudes (2nd ed.). Belmont, CA: Wadsworth.

Morris, D. (1977). Manwatching: Field Guide to Human Behavior. London, United Kingdom: Triad Panther.

Manusov, V. \& Patterson, M. L. (2006). The Sage Handbook of Nonverbal Communication. Thousand Oaks, CA: Sage.

Mazzei, L. A. (2008). Silence Speaks: Whiteness Revealed in the Absence of Voice. Teaching and Teacher Education: An International Journal of Research and Studies, vol.24, pp.1125-1136.

Nolen-Hoeksema, S. (1987). Sex Differences in Unipolar Depression: Evidence and Theory. Psychological Bulletin, vol.101, pp.259-282.

NakaYama, \& Lisa N, Flores (2011). (Eds.). Readings in intercultural Communication: Experiences and contexts pp138-149Boston Mcgraw Hill. Owen Hargie, Skilled Interpersonal Interaction: Research, Theory, and Practice, 5th ed. London: Routledge.

Otto, J. (1922). The Woman Language: Its Nature, Development and Origin. London: Allen and Unwin, pp.237-54.

Onwuegbuzie, A. J., Leech, N. L. \& Collins, K. M. T. (2010). Innovative Data Collection Strategies in Qualitative Research. The Qualitative Report, vol.15, pp.696-726. Retrieved from: http:/www.nova.edu/ssss/QR/QR15-3/onwuegbuzie.pdf

Perry, L. A. M., Turner, L. H., \& Sterk, H. M. (1992). Constructing and Reconstructing Gender: The Links among Communication, Language and Gender. Albany: State Univ. of New York Press. 
Richard A. Lippa (2002) Gender, Nature and Nurture Taylar \& Francis Group, England. Reiman Tonya, Gender Differences in Communication, http://www.bodylanguage university.com/public/213.cfm

Siddiqui, Shahid (2014). Language, Gender and Power the Politics of Representation and Hegemony in South Asia, Karachi, Oxford University Press.

Tannen, D. (1990) You Just Don't Understand: Women and Men in Conversation. William Morrow \& Co Inc., USA.

Tenenbaum, HR., Ford, S. \& Alkhedairy, B. (2010). Telling Stories: Gender Differences in Peer's Emotion Talk and Communication Style. 10.1348/2044-835X.002003

Vygotsky, L. S. (1962). Thought and Language. Cambridge MA: MIT Press Cultural Communication in Intercultural Contact, pp.193-194. Hillsdale NJ : Earlbaum.

Wood Julia, (2006). Gendered Lives, Cengage Learning .

Warren, G., Schertler, E., \& Bull, P. (2009). Detecting Deception from Emotional and Unemotional Cues. Journal of Nonverbal Behavior, vol.3, pp.59-69.

Young, Iris Marion (1990). Throwing Like a Girl and Other Essays in Feminist Philosophy and Social Theory. Bloomington: Indiana University Press.

Dr. Aliyah Ali is an Assistant Professor in the Centre of Excellence for Women's Studies, University of Karachi.

Dr. Shagufta Nasreen is an Assistant Professor in the Centre of Excellence for Women's Studies, University of Karachi.

Prof. Dr. M. Abuzar Wajdi is Directorate, Institute of Health \& Business Management (IOHBM), Jinnah Sindh Medical University, Karachi, Pakistan. 